\title{
Una mordedura misteriosa: la experiencia del otro en el «Cántico espiritual» de san Juan de la Cruz y «L'Après-midi d'un faune» de Stéphane Mallarmé

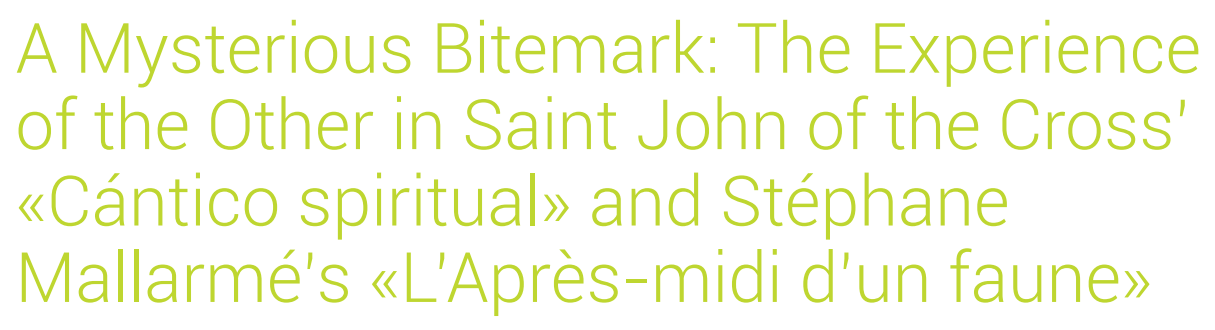

\section{Felix K. E. Schmelzer}

Universidad de los Andes

CHILE

fschmelzer@uandes.cl

[Hipogrifo, (issn: 2328-1308), 8.1, 2020, pp. 567-577]

Recibido: 30-10-2019 / Aceptado: 18-12-2019

DOI: http://dx.doi.org/10.13035/H.2020.08.01.38

Resumen. Como parte de un estudio comparado que pretende detectar elementos de la teología negativa en las obras de san Juan de la Cruz y Stéphane Mallarmé, el presente trabajo compara dos poemas en concreto, el «Cántico espiritual» y «L'Après-midi d'un faune», con vistas a la experiencia del otro.

Palabras clave. San Juan de la Cruz; Stéphane Mallarmé; Teología negativa; «Cántico espiritual»; «L'Après-midi d'un faune».

Abstract. Forming part of a more extended comparison between the work of Saint John of the Cross and Stéphane Mallarmé with regard to elements of Negative

1. El presente trabajo se enmarca en el proyecto FONDECYT 11160382 ( Negative Theology and Negative Poetics: A Comparative Study of Saint John of the Cross and Stéphane Mallarmé»), financiado por CONICYT, Chile. 
Theology, the present essay compares two poems directly: «Cántico espiritual» and «L'Après-midi d'un faune».

Keywords. Saint John of the Cross; Stéphane Mallarmé; Negative Theology; «Cántico espiritual», «L'Après-midi d'un faune».

La mística cristiana ha sido comparada con la poesía lírica moderna² en varias ocasiones. Henri Bremond se encuentra entre los primeros en destacar paralelos y similitudes entre ambas vertientes (Prière et poésie, 1926) ${ }^{3}$, y varios estudios han sido publicados desde entonces ${ }^{4}$. En el marco de tal comparación, un elemento importante a considerar es la idea de que el arte y la poesía pueden ser medios para experimentar lo divino. Esa idea, reforzada, además, por la noción platónica del poeta entusiasmado ${ }^{5}$, domina la estética romántica y resuena todavía durante la primera mitad del siglo XX. Un buen ejemplo de una traslación de la experiencia de lo divino al ámbito estético es la famosa definición de la religión como «sentido y gozo para lo infinito» (Schleiermacher) ${ }^{6}$. En este contexto, tanto la experiencia mística como la experiencia poética se conciben como un contacto, o incluso como una unión con lo radicalmente otro.

A través de un estudio comparado de dos representantes particularmente importantes y modélicos, san Juan de la Cruz y Stéphane Mallarmé, espero contribuir a una concreción y comprensión más profunda de los paralelos mencionados. ¿Por qué estos dos autores? Sin duda, la obra del Carmelita marca un, si no el punto culminante de la poesía mística cristiana, y la importancia de Mallarmé, no solo para la poesía lírica sino también para la teoría literaria del siglo XX es igualmente innegable? ${ }^{7}$. Como parte de ese estudio, el presente trabajo compara dos poemas en concreto, el «Cántico espiritual» de san Juan de la Cruz y «L'Après-midi d'un faune»

\footnotetext{
2. Me refiero, en particular, a la poesía occidental de Baudelaire en adelante.

3. Bremond adscribe tanto al místico como al poeta la capacidad de experimentar lo divino. Sin embargo, el segundo, en cuanto dedicado a la creación poética, se une y se separa al mismo tiempo: «Le poète, en tant que poète, ne s'unit au réel que pour s'en desunir aussitôt» (1926, p. 213), mientras que el místico, con la gracia divina, es capaz de entregarse enteramente a Dios en una unión voluntaria. 4. Algunos ejemplos: Walter Benjamin («Das Kunstwerk im Zeitalter seiner technischen Reproduzierbarkeit») nombra a Mallarmé el primer representante de una «teología negativa de las artes» (1961, p. 156); Alois Haas reconoce en Paul Valéry y Fritz Mauthner dos representantes de una mística sin Dios particularmente moderna (2004, pp. 450-462); entre los trabajos más recientes, Cirlot y Vega subrayan que la mística es un «fenómeno fundador de la identidad espiritual de Europa» (2006, p. 9) cuyas huellas se detectan claramente en el arte (incluyendo la arquitectura) y el pensamiento del siglo xx; y un trabajo coordinado por Schmelzer y Ugarte (2018) estudia la gran influencia de san Juan de la Cruz en la poesía del XX.

5. Es decir, «tocado por los dioses» (o musas). El diálogo decisivo es el Ion (534c-e), donde se aplica

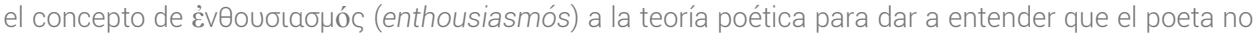
es autor de su mensaje, sino un «mensajero de los dioses» (hermeneus tôn theôn) que no sabe qué está diciendo.

6. Über die Religion, p. 36.

7. Con vistas al (post-)estructuralismo, Roland Barthes admite: «all we do is copy Mallarmé» (1970, p. 51).
} 
de Stéphane Mallarmé, con vistas a la experiencia del otro (veremos en qué medida ese 'otro', también en el caso de Mallarmé, puede ser considerado como 'divino').

En un primer análisis he llegado a la conclusión de que existen cuatro paralelos llamativos entre la poesía y en el pensamiento de ambos autores, que se revelan si uno conserva cierto nivel de abstracción ${ }^{8}$ : en primer lugar, tanto san Juan de la Cruz (en cuanto a poeta) como el joven Mallarmé se consideran un medio a través del cual un espíritu trascendente se expresa a sí mismo; en segundo lugar, la deconstrucción del lenguaje poético juega un papel central en sus obras, sobre todo en los pasajes relacionados con la experiencia del otro; en tercer lugar, ambos autores se enfocan en la idea de una purificación del alma con vistas a la superación de la dimensión material; en cuarto y último lugar, la idea fundamental de su obra parece ser el verdadero autoconocimiento, es decir, la autocontemplación del alma individual que lleva a la autocontemplación del espíritu universal dentro del poeta. En relación con el último punto, se podría añadir - simplificando- que la poesía de san Juan de la Cruz pretende expresar ese proceso en imágenes poéticas, mientras que la poesía de Mallarmé pretende desplegar ese proceso en el espacio del poema. Sin embargo, los límites entre ambas perspectivas son borrosos ${ }^{9}$.

Volviendo a los poemas, los dos pueden entenderse como variantes de la poesía bucólica o pastoril. "L'Après-midi d'un faune» es designado explícitamente como égloga («églogue») en el subtítulo de la primera edición (1876), y el «Cántico» de san Juan de la Cruz es una paráfrasis del Cantar de los cantares bíblico, integrante a su vez de la tradición de la poesía bucólica semítica. En el caso del «Cántico», habría que añadir la influencia decisiva de la poesía bucólica petrarquista de Garcilaso, y también la traducción 'petrarquizante', en endecasílabos, del Cantar de los cantares que hizo fray Luis de León. La modificación de las normas propias del género se verifica en ambos casos en que no es el pastor (o los pastores) que canta, sino la pastora/esposa ${ }^{10}$ (en el «Cántico») y un fauno (en el caso del poema de Mallarmé). Utilizando un recurso típico, ambas figuras lamentan la ausencia del otro: la esposa a su «esposo», el fauno a dos ninfas ${ }^{11}$.

Lo más importante en el contexto de mi trabajo es que, en ambos poemas, el discurso erótico está directamente vinculado con un discurso sagrado o espiritual. Esto es más obvio en el «Cántico» ya que, siguiendo la tradición de la mística nupcial, san Juan elaboró ese texto sobre la base de la alegoría del matrimonio espiritual ${ }^{12}$, en el marco de la cual el alma humana es considerada la esposa, mientras

8. Schmelzer, 2018, pp. 505-523.

9. Desde una perspectiva hermenéutica, ese proceso de auto-contemplación tiene que desplegarse también en su expresión imaginativa, y precisamente en la medida en que el lector es capaz de comprenderlo. 10. Como sugieren las referencias a «ganado» (estrofas 26 y 28, Cántico B), la esposa del «Cántico» revela características de una pastora.

11. El hecho de que son dos ninfas se explica, entre otros factores, por la tradición. Así, en la primera égloga de Virgilio, Galatea y Amaryllis representan dos caracteres femeninos opuestos: insondable y destructiva como el mar la una, racional y reconfortante la otra. Ver von Albrecht, 2001, p. 274.

12. Cánonicos, en este contexto, son las exégesis del Cantar de los cantares por parte de Orígenes y, sobre todo, Bernardo de Claraval. Ver Leppin, 2007, pp. 58-70. 
que Dios (Jesucristo) se vuelve el esposo ${ }^{13}$. En el poema de Mallarmé, la idea de un discurso sagrado subyacente sorprende a primera vista, sobre todo si tomamos en consideración que algunos críticos -Pascal Durand, por ejemplo- designan «L'Après-midi» como «pornografía» ${ }^{14}$. En el marco de tal lectura, la siringa del fauno, ya por definición una criatura de insaciable apetito sexual, se transforma en un símbolo fálico, y el acto creador o poético que representa dicho instrumento ${ }^{15}$ deviene acto erótico agresivo, una 'violación' del papel. Y es cierto, pero aún hay más.

En comparación con el «Cántico», la dificultad de «L'Après-midi» reside en el hecho de que no existe de antemano una clave de interpretación como el de la mística nupcial (lo que no quiere decir que el poema de san Juan sea fácilmente comprensible, nada menos cierto que eso). Mi tesis es que el poema de Mallarmé alegoriza, de manera erótica y muy original (es el fauno quien habla), no solo el acto creador, sino el intento del poeta moderno de reconquistar la dimensión espiritual ${ }^{16}$. Hay que tener en consideración que Mallarmé concibió esa égloga como 'antídoto' contra otro poema famoso, «Hérodiade», que, según él, le había «esterilizado» ${ }^{17}$. Es una palabra fuerte. ¿Por qué la usa? «Hérodiade» personifica una belleza absoluta que existe solo por sí misma: en una escena nuclear del poema, se aparta de la ventana y el «azur seráfico» que muestra para contemplarse a sí misma en el espejo, un cambio metafórico decisivo. Es la idea del arte por el arte que excluye la dimensión del otro, que Mallarmé percibió como infecunda y hostil al momento de manifestarse en su obra, un aspecto olvidado por muchos críticos. Con «L'Après-midi», esa dimensión vuelve, y con ella la idea de fertilidad e inspiración ${ }^{18}$. Y la otredad no puede ser meramente material. Como subraya Bonnefoy, es improbable que Mallarmé, tan «enamorado del Absoluto», tuvo en mente nada más que un encuentro erótico al momento de redactar el poema ${ }^{19}$. Las ninfas, por tanto, remiten para Bonnefoy a una existencia «inmaterial, divina» 20 , y el supuesto encuentro con ellas a un «éxtasis espiritual ${ }^{21}$. La tesis del intento de una reconquista espiritual puede ser sostenida también desde una perspectiva metafórica: en el poema, las ninfas forman parte de

\footnotetext{
13. Hay que añadir que una separación nítida entre las dimensiones erótica (material) y espiritual no existe, ya que ambos se unen en el misterio de la encarnación, misterio nuclear tanto del cristianismo como de la obra de san Juan de la Cruz. Thompson (2002, pp. 370-371) concluye su estudio con esa idea. 14. Durand, 1998, p. 106.

15. Von Albrecht (2001, p. 270) comenta que la bucólica, ya desde Teócrito, es un género afín a la autoreflexión poética. Mallarmé sigue esa línea de tradición y la modifica al mismo tiempo, ya que es el fauno quien habla.

16. La idea de superar una visión meramente materialista del universo es clave en Mallarmé. Ver, en este contexto, Schmelzer, en prensa.

17. En 1865, escribe a su amigo Cazalis: «J'ai laissé Hérodiade pour les cruels hivers: cette œuvre solitaire m'avait stérilisé, et dans l'intervalle, je rime un intermède héroïque, don't le héros est un faune» (Correspondance, p. 131). Como indica Bertrand Marchal (1992, p. 207), en los años decisivos de 1865 y 1866, Mallarmé trabajó en «Hérodiade» durante los inviernos; y en el poema del fauno, cuya versión final con título definitivo no fue publicada hasta 1876, durante las primaveras.

18. Es significativo, por supuesto, que ese encuentro ya no se exprese con metáforas cristianas.

19. Bonnefoy, 1992, p. XXIII.

20. Bonnefoy, 1992, p. XXV.

21. Bonnefoy, 1992, p. XXVI.
} 
un campo semántico de «blancura», «pureza» y «virginidad» que, desde la poesía temprana de Mallarmé, implica la idea de lo sagrado22.

Dejando en claro que el discurso erótico puede entenderse como vinculado directamente con un discurso espiritual también en el poema de Mallarmé, podemos definir el punto de partida como sigue: en ambos poemas, el hablante lírico (una esposa, un fauno) se sitúa en un ambiente bucólico y entra en diálogo con la naturaleza; en ambos, lamenta la ausencia del otro (el esposo-Dios, las ninfas-el Espíritu/la inspiración poética) y anhela su presencia; en ambos, parece tener lugar algún contacto, aunque, como veremos, no queda claro cómo ese contacto se realizó ya que los versos que sugieren un contacto directo, o incluso una unión, son altamente indeterminados e imprecisos.

Vamos a comparar directamente algunos pasajes que refieren la experiencia del otro. Para empezar, dos extractos que sugieren la existencia de huellas que dicha experiencia dejó en el hablante y, de esa manera, un contacto o toque en el pasado:

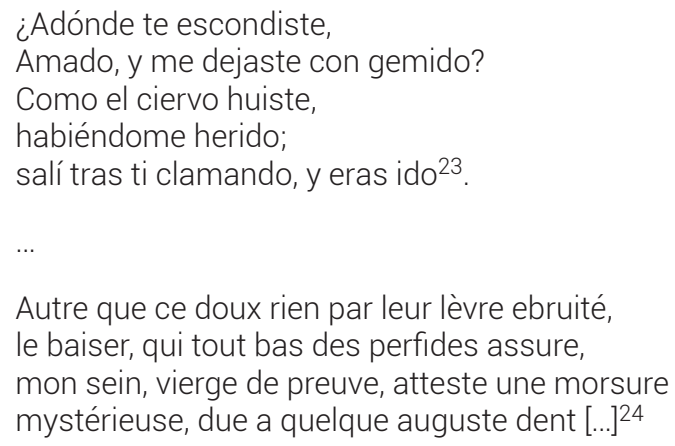

La primera estrofa del «Cántico» introduce la metáfora de la herida amorosa (v. 4), frecuente no solo en la poesía petrarquista, sino también en la literatura mística cristiana. En el contexto de la mística, puede entenderse como una apertura del sujeto hacia Dios que aumenta la sensibilidad y percepción del mismo. A veces, como también en el poema de san Juan de la Cruz, esa metáfora introduce a otra, la de la muerte (mors mystica), que designa una sola apertura, por así decirlo o, en otras palabras, la inclusión momentánea del yo en el otro al momento de la supuesta unión ${ }^{25}$. El pasaje citado es uno entre muchos en mencionar la metáfora

23. Todas las citas de san Juan de la Cruz según Obras completas, ed. Eulogio Pacho.

24. De aquí en adelante, cito la versión del poema según Poésies, ed. Bertrand Marchal.

25. Von Balthasar (1984, p. 500) describe los «toques» y «heridas» en la obra de san Juan de la Cruz como «una experiencia casi mortal, comparable con el beso al inicio del Cantar de los Cantares». La mors mystica es un punto crítico, ya que puede entenderse como unión esencial o sustancial, una idea incompatible con el cristianismo. Consciente de ese peligro, san Juan de la Cruz repite en sus comentarios que no se trata de una unión sustancial. Es un buen ejemplo de cómo un dogma concreto puede entrar en conflicto con la indeterminación del lenguaje poético. 
de la herida, que el poema elabora con una variación notable (ver las estrofas 2, 6, 7, 8, 9, 34 de la primera versión).

Muy parecida a la herida amorosa, la «mordedura misteriosa» que dejó «algún diente sublime» en el pecho del fauno es una metáfora clave en el poema de Mallarmé, ya que es la única formulación que parece remitir directamente a una existencia real de las ninfas (recuérdese que el fauno, a lo largo del texto, no es capaz de averiguar si las ninfas son solo un producto de su fantasía ${ }^{26}$ ). De acuerdo con la idea de la mordedura, el pasaje citado invierte, y esto es notable, la idea de la virginidad: ahora no son las ninfas, sino, al parecer, el pecho del fauno el que es virginal. Por otra parte, la formulación «mi pecho, virginal de pruebas, da testimonio de una mordedura» es paradójica y parece anularse a sí misma, ya que sugiere que las pruebas y, por lo tanto, el testimonio de la mordedura, no existen. Así, nada queda claro.

Ahora me gustaría poner en diálogo dos apartados que sugieren una revelación del otro, en el sentido paradójico de una desocultación oculta (en el poema de Mallarmé, los pasajes entrecomillados y en cursiva son los que refieren directamente a los recuerdos del supuesto encuentro del fauno):

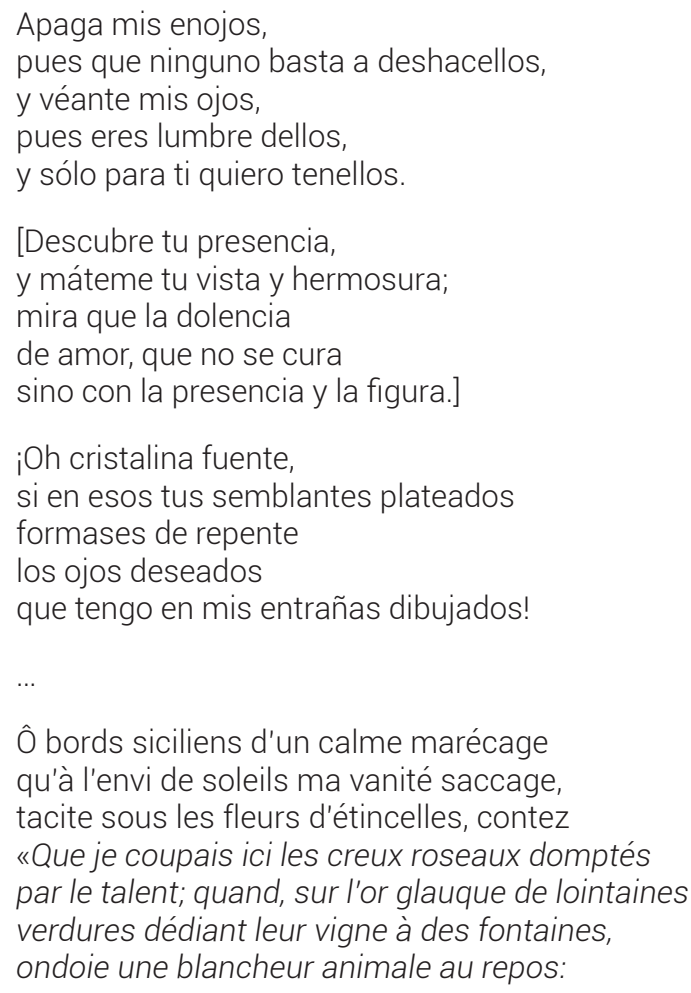


et que'au prélude lent où naissent les pipeaux

ce vol de cygnes, non! de naïades se sauve

ou plonge...»

Este pasaje es tal vez el más enigmático del poema de san Juan de la Cruz. El escenario, que gira en torno a un sugerido espejismo de la pastora - de sus ojos, más precisamente- en una «cristalina fuente», es curioso, y la pregunta central, formulada por Teuber, es: ¿quién mira a quién? ${ }^{27}$ Es significativo en este contexto el añadido de una estrofa (en la cita entre corchetes) en la segunda versión del poema. Una probable razón de esta modificación por parte del autor es que en la segunda versión es más claro que son los ojos de Él los que aparecen en el movedizo espejo del agua, y no los ojos de ella. Y parece lógico (si «lógico» es una palabra que puede usarse aquí), ya que, en palabras de Hans Urs von Balthasar, «Dios solo puede ser reconocido por Dios» ${ }^{28}$. Hay que añadir que esa revelación es hipotética en el poema, es decir, un deseo; lo decisivo es lo que no queda dicho ${ }^{29}$. Sin embargo, en los versos siguientes, el esposo tomará la palabra por primera vez, lo que hace suponer que ya había aparecido.

Equivalentemente enigmática e indeterminada es la revelación de las ninfas en el poema de Mallarmé. En su aparente diálogo con la naturaleza, reminiscencia de la tradición bucólica, el fauno parece dictar la respuesta («Ô bords siciliens... / ... contez»). ¿Entonces se trata de un mero deseo o es un sueño? Es muy significativo, además, que las ninfas, cuya imagen concreta se disuelve porque parecen ser cisnes ${ }^{30}$ («ce vol de cygnes, non! de naïades»), se revelan justo al momento en que el fauno corta la caña para construir su zampoña. Así, se sugiere la pregunta subyacente del poema en cuanto a si lo otro solo es producto de la creación poética ${ }^{31}$. Y hay aun otra paradoja, señalada por Durand: parece que la zampoña del fauno es la causa tanto de la aparición de las ninfas como de su huida. Por último, curiosamente, como en el "Cántico», el medio de esa desocultación oculta es el agua, agua que está en movimiento («ondoie»).

Para concluir (si es que se puede), veamos dos apartados que sugieren un contacto directo o, incluso, una unión con el otro:

\section{Teuber, 2003, p. 297. \\ 28. Von Balthasar, 1984, p. 468.}

29. En este contexto, Ynduráin comenta: «en realidad nada se nos dice del proceso [...]. Es el lector quien debe, desde los resultados o efectos, reconstruir el proceso, proceso que nunca será nítido en sus deta\|les circunstanciales, lógicos, etc., aunque sí en la intensidad» (1983, p. 88).

30. En la poesía juvenil de Mallarmé, los cisnes se relacionan directamente con lo sagrado. Así, en un poema del año 1859, los ángeles son «cisnes puros de celestes nidos»: «Seigneur, merci! toi qui nous changes / Les nuits d'exil en jours bénis! / N'était-ce assez te ton chœur d'anges, / Cygnes purs des célestes nids?» (Euvres complètes, I, p. 174).

31. Esa pregunta (pre)ocupa a Mallarmé a lo largo de su trayectoria poética. Es ejemplar una frase de una carta del año 1866 (nótese la ironía): «Oui, je le sais, nous ne sommes que de vaines formes de la matière,-mais bien sublimes pour avoir inventé Dieu et nôtre âme» (Correspondance, p. 161; curiosamente, en esta misma carta también menciona al fauno). Creo que Mallarmé no nos da una respuesta definitiva en su obra, y eso, precisamente, es lo interesante. 
¡Apártalos, Amado, que voy de vuelo!

Esposo Vuélvete, paloma,

que el ciervo vulnerado

por el otero asoma

al aire de tu vuelo, y fresco toma.

$\ldots$

Mon crime, c'est d'avoir, gai de vaincre ces peurs trâitresses, divisés la touffe échevelée

de baisers qui les dieux gardaient si bien mêlée;

car, à peine j'allais cacher un rire ardent

sous les replis heureux d'une seule (gardant

par un doigt simple, afin que sa candeur de plume

se teignît à l'émoi de sa sœur qui s'allume,

la petite, naive et ne rougissant pas:)

que de mes bras, défaits par de vagues trépas,

cette proie, à jamais ingrate, se délivre

sans pitié du sanglot dont j'étais encore ivre.

Aquí es muy difícil arribar a una comprensión unívoca. En el poema de san Juan, la sugerida apariencia de los ojos del esposo en el espejo del agua ahora se fundamenta por la presencia de su voz justo al momento del éxtasis del alma (el «vuelo» de la paloma). El pasaje es decisivo, ya que ambas voces se unen en un solo verso por primera y única vez en el poema. Los verbos, además, están en presente, contrariamente a las demás descripciones de un supuesto encuentro, memorizado o anhelado, en el pasado o futuro. Retomando la metáfora inicial, es significativo que el esposo se refiere a sí mismo en tercera persona, como "ciervo vulnerado», afirmación que podría leerse en clave teológica como una pregunta: ¿Dios se reconoce encarnado, es decir, vulnerable? ${ }^{32}$ El lugar del encuentro, como sugieren el «vuelo»y el «otero», se sitúa en los aires purificados de un arriba. En el contexto del poema, el pasaje citado introduce las enigmáticas estrofas 13 a 15 (primera versión), que se construyen sobre la base de un gran número de paradójicas impresiones que no se estructuran alrededor de ningún verbo. Esa ausencia de la predicación y el uso simultáneo de la acumulación pueden verse como un recurso poético para expresar una experiencia $\sin$ límites $^{33}$ del otro. Parece que el hablante se encontrara en un estado de éxtasis calmado, completamente lleno del otro, o habiendo entrado en él completamente, lo que se adivina en las palabras de la esposa que a continuación leemos: «Mi Amado, las montañas, / los valles solitarios nemorosos, / las ínsulas

32. Es sugerente el comentario del propio san Juan: «Compárase el Esposo al ciervo, porque aquí por el ciervo entiende a sí mismo. Y es de saber que la propiedad del ciervo es subirse a los lugares altos y, cuándo está herido, base con gran priesa a buscar refrigerio a las aguas frías y, si oye quejar a la consorte y siente que está herida, luego se va con ella y la regala y acaricia. Y así hace ahora el Esposo, porque, viendo la Esposa herida de su amor, él también al gemido de ella viene herido del amor de ella; porque en los enamorados la herida de uno es de entrambos, y un mismo sentimiento tienen los dos» (Cántico espiritual, 13.9).

33. Cada predicación es una limitación. 
extrañas, los ríos sonorosos, / el silbo de los aires amorosos. // La noche sosegada / en par de los levantes del aurora, / la música callada, / la soledad sonora, / la cena que recrea y enamora...».

No es menos difícil el apartado de Mallarmé, sobre todo la descripción de las ninfas como dos en una, tal vez la paradoja nuclear del poema. La actitud masculina del hablante frente a su 'presa' va acompañada por un discurso de culpabilidad («mon crime»). El contacto, si ha tenido lugar (como ya se ha dicho, el fauno cree acordarse de un contacto directo real, pero no sabe si su memoria le engaña), es descrito en términos de una penetración activa o, incluso, una violación; es una actitud muy opuesta a la del hablante en el poema de san Juan de la Cruz. La supuesta unión con el otro, de nuevo una paradoja, causa al mismo tiempo una separación, aunque momentánea, de aquella unidad primordial de ambas, que, sin embargo, parece ya llevar en sí misma la semilla de la dualidad. En el contexto del poema, esa escena erótica es precedida por un rapto prometeico de las dos ninfas íntimamente entrelazadas (vv. 71-74). Estamos en presencia, por tanto, de la doble transgresión de un límite, marcado por el «himen» (v. 34). Así, las ninfas huyen (en apariencia, en el preciso momento del éxtasis), y el fauno, al final del poema, termina previendo su «castigo seguro» (v. 103).

Hemos visto en este breve recorrido que, a pesar de la diferencia fundamental de perspectivas -en el poema de san Juan de la Cruz, el encuentro con lo radicalmente otro se expresa desde la perspectiva de una mujer que quiere desposarse, en el de Mallarmé, desde la de un fauno que roba a dos ninfas para satisfacer su apetito sexual- destacan paralelos notables entre ambos textos. El ambiente bucólico en el que el encuentro con el otro se sitúa; la metáfora de la herida amorosa, modificada en «L'Après-midi» en forma de «mordedura misteriosa»; la apariencia del otro como desocultación oculta en medio de un agua movediza, precedida en ambos casos por una especie de ritual de invocación (el llamamiento al esposo en el espejo del agua, la construcción de la zampoña y el «preludio» que parece tocar el fauno). Por otra parte, es precisamente la diferencia de perspectivas la que da lugar a una diferencia fundamental en el modo de expresar la posibilidad del contacto directo o, incluso, la unión con el otro: la esposa, al parecer, se entrega y, por consecuencia, es acogida afectuosamente por el esposo; el fauno, en cambio, como un intruso posesivo, se apodera, por lo que las ninfas huyen de él. De acuerdo con ello, en el momento decisivo, la pastora pasa a estar literalmente dentro del otro, mientras que el fauno, en apariencia, queda fuera. La tensión en la forma de expresar la experiencia de contacto, en el caso de Mallarmé, refleja la relación del poeta con su fuente de inspiración: en oposición al místico, no querrá "solamente" experimentar «la cena que recrea y enamora», es decir, el misterio amoroso de la creación, sino utilizarlo para su propia creación, consciente de la culpa que su deseo conlleva.

Quiero insistir en que, a pesar de lo dicho, la pregunta de si el supuesto contacto con el otro ha tenido lugar, no es respondida de modo definitivo en ambos textos. El intento por aclarar el mensaje encerrado en estos poemas siempre transita el terreno de las suposiciones. Lo inmediato queda indecible. En relación con este punto, la idea de que la experiencia mística tiene lugar dentro del poema, y tal vez 
solo allí, puede resultar relevante también para el «Cántico». En otras palabras, ¿es la poesía mística la verbalización de una experiencia real que existe fuera de la palabra, o es la forma -lingüística, musical o artística en general- necesaria para poder experimentar lo divino (o, tal vez menos pretenciosamente, para poder asimilar tal experiencia)? Si aceptamos como respuesta la segunda posibilidad, también la obra de Mallarmé da lugar a, al menos, la posibilidad de una «presencia real» ${ }^{34}$ en el lenguaje.

\section{BiBLIOgRAFÍA}

Barthes, Roland. «Conversation with Stephen Heath», en Signs of the Times, Cambridge, Cambridge University Press, 1970, pp. 41-51.

Benjamin, Walter, «Das Kunstwerk im Zeitalter seiner technischen Reproduzierbarkeit», en Illuminationen, Frankfurt am Main, Suhrkamp, 1961, pp. 148-184.

Bonnefoy, Yves, «Préface», en Stéphane Mallarmé, Poésies, ed. Bertrand Marchal, Paris, Gallimard, 1992, pp. VII-XXXVI.

Bremond, Henri, Prière et poésie, Paris, Grasset, 1926.

Cirlot, Victoria, y Vega, Amador (eds.), Mística y creación en el siglo XX, Barcelona, Herder, 2006.

Durand, Pascal, Pascal Durand commente «Poesíes» de Stéphane Mallarmé, Paris, Gallimard, 1998.

Haas, Alois M., Mystik im Kontext, München, Fink, 2004.

Juan de la Cruz, Obras completas, ed. Eulogio Pacho, Burgos, Monte Carmelo, 2010.

Mallarmé, Stéphane, Correspondance. 1854-1898, ed. Bertrand Marchal, Paris, Gallimard, 2019.

Mallarmé, Stéphane, Euvres complètes, I, ed. Bertrand Marchal, Paris, Gallimard, 1998.

Mallarmé, Stéphane, Poésies, ed. Bertrand Marchal, Paris, Gallimard, 1992.

Marchal, Bertrand, «L'Après-midi d'un faune» [comentario], en Stéphane Mallarmé, Poésies, ed. Bertrand Marchal, Paris, Gallimard, 1992, pp. 206-218.

Plato, Ion, en Werke, I, trad. Friedrich Schleiermacher, ed. Heinz Hofmann, Darmstadt, WBG, 2016.

34. En su famoso libro Real Presences, Steiner introduce su tesis principal como sigue: «any coherent understanding of what language is and how language performs [...] is, in the final analysis, underwritten by the assumption of God's presence. I will put forward the argument that the experience of aesthetic meaning in particular, that of literature, of the arts, of musical form, infers the possibility of this "real presence"» $(1989$, p. 3) 
Reisewitz, Perry, «Stéphane Mallarmé: "L'Après-midi d'un faune"», en Interpretationen. Französische Gedichte des 19. und 20. Jahrhunderts, ed. Hartmut Köhler, Stuttgart, Reclam, 2001.

Schleiermacher, Friedrich, Über die Religion, Stuttgart, Reclam, 1969.

Schmelzer, Felix, «(Neo)Platonic Thought in Saint John of the Cross and Stéphane Mallarmé», Hipogrifo. Revista de literatura y cultura del Siglo de Oro, 6.2, 2018, pp. 505-523.

Schmelzer, Felix, «Mallarmé und die metaphorischen Kreise des Nichts», Romanische Forschungen, 132.1, 2020, pp. 45-57.

Schmelzer, Felix, «Feathery Traces: The (Dis)Appearance of the Angel in the Work of Mallarmé», Religion \& Literature, en prensa.

Schmelzer, Felix, y Ugarte, María Ignacia (coords.), San Juan de la Cruz y la lírica moderna, Hipogrifo. Revista de literatura y cultura del Siglo de Oro, 6.2, 2018, pp. 365-538.

Steiner, George, Real Presences, Chicago, University of Chicago Press, 1989.

Teuber, Bernhard, Sacrificium litterae. Allegorische Rede und mystische Erfahrung in der Dichtung des heiligen Johannes vom Kreuz, München, Fink, 2003.

Thompson, Colin P., Canciones en la noche. Estudio sobre san Juan de la Cruz, Madrid, Trotta, 2002.

Von Albrecht, Michael, «Nachwort», en Vergil, Bucolica, ed. Michael von Albrecht, Stuttgart, Reclam, 2001, pp. 263-285.

Von Balthasar, Hans Urs, Herrlichkeit. Eine theologische Ästhetik, II.2, Einsiedeln, Johannes Verlag, 1984.

Ynduráin, Domingo, «Introducción», en san Juan de la Cruz, Poesía, ed. Domingo Ynduráin, Madrid, Cátedra, 2015 [1983], pp. 11-237. 